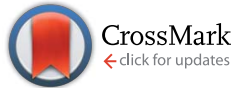

Cite this: Chem. Sci., 2016, 7, 6928

Received 21st April 2016

Accepted 4th July 2016

DOI: $10.1039 / c 6 s c 01754 a$

www.rsc.org/chemicalscience

\section{Multi-electron reactivity of a cofacial di-tin(II) cryptand: partial reduction of sulfur and selenium and reversible generation of $\mathrm{S}_{3}{ }^{\cdot-} \dagger$}

\author{
Julia M. Stauber, ${ }^{a}$ Peter Müller, ${ }^{a}$ Yizhe Dai, ${ }^{c}$ Gang Wu, ${ }^{\star c}$ Daniel G. Nocera*b \\ and Christopher C. Cummins*a
}

Cofacial bimetallic tin(॥) $\left(\left[\mathrm{Sn}_{2}(m \mathrm{BDCA}-5 \mathrm{t})\right]^{2-}, 1\right)$ and lead(॥) $\left(\left[\mathrm{Pb}_{2}(m \mathrm{mDCA}-5 \mathrm{t})\right]^{2-}, 2\right)$ complexes have been prepared by hexadeprotonation of hexacarboxamide cryptand $m \mathrm{BDCA}-5 \mathrm{t}-\mathrm{H}_{6}$ together with double $\mathrm{Sn}(\Perp)$ or $\mathrm{Pb}(\Perp)$ insertion. Reaction of 1 with elemental sulfur or selenium generates di-tin polychalcogenide complexes containing $\mu-E$ and bridging $\mu-E_{5}$ ligands where $E=S$ or $S e$, and the Sn(॥) centers have both been oxidized to $\mathrm{Sn}(\mathrm{IV})$. Solution and solid-state UV-Vis spectra of $\left[\left(\mu-S_{5}\right) S n_{2}(\mu-S)(m B D C A-5 t)\right]^{2-}(4)$ indicate that the complex acts reversibly as a source of $S_{3}{ }^{--}$in DMF solution with a $K_{\text {eq }}=0.012 \pm 0.002$. Reductive removal of all six chalcogen atoms is achieved through treatment of $\left[\left(\mu-E_{5}\right) S_{2}(\mu-E)(m B D C A-\right.$ $5 \mathrm{t})]^{2-}$ with $\mathrm{PR}_{3}\left(\mathrm{R}={ }^{t} \mathrm{Bu}, \mathrm{Ph}, \mathrm{O}^{\mathrm{i}} \mathrm{Pr}\right)$ to produce six equiv. of the corresponding $\mathrm{EPR}_{3}$ compound with regeneration of di-tin(॥) cryptand complex 1 .

\section{Introduction}

Multi-electron transfer reactions are an area of intense interest due to their key role in both biological ${ }^{1}$ and synthetic systems for the activation and transformation of small molecules germane to energy conversion. These systems have the ability to accommodate and deliver multiple electrons to reaction substrates at one time, and typically feature two or more redox active metal ions confined within a single structural unit. Synthetic organometallic complexes that undergo multi-electron redox processes have been extensively studied for their applications in electrocatalysis, ${ }^{2}$ sensing, ${ }^{3}$ homogeneous, ${ }^{4}$ and heterogeneous ${ }^{5}$ catalysis. Many of these systems are based upon face-to-face diporphyrins, in which two metalloporphyrins are rigidly linked together in a cofacial arrangement. ${ }^{6}$ Complexes of this type have received considerable interest due to their ability to carry out multi-electron processes such as oxygen reduction, ${ }^{7}$ nitrogen reduction, ${ }^{8}$ and $\mathrm{H}_{2} \mathrm{O}_{2}$ disproportionation. ${ }^{9}$

We have shown previously that macro-bicyclic hexacarboxamide cryptand molecules, ${ }^{\mathbf{1 0}}$ in hexa-deprotonated form, serve as excellent frameworks engendering cofacial transition-metal

\footnotetext{
${ }^{a}$ Department of Chemistry, Massachusetts Institute of Technology, 77 Massachusetts Avenue, Cambridge,MA,02139-4307,USA.E-mail: ccummins@mit.edu

${ }^{b}$ Department of Chemistry and Chemical Biology, Harvard University, 12 Oxford Street, Cambridge, MA 02138-2902, USA. E-mail: dnocera@fas.harvard.edu

'Department of Chemistry, Queen's University, 90 Bader Lane, Kingston, Ontario, Canada K7L 3N6. E-mail: gang.wu@chem.queensu.ca

$\dagger$ Electronic supplementary information (ESI) available: Experimental procedures and crystallographic details. CCDC 1469593, 1469595 and 1469596. For ESI and crystallographic data in CIF or other electronic format see DOI: 10.1039/c6sc01754a
}

bimetallic systems with a range of intermetal distances; ${ }^{\mathbf{1 0 , 1 1}}$ these systems are distinguished from bis-porphyrin constructs in that the metal ion coordination environment is trigonal rather than tetragonal. While transition metal complexes that carry out multi-electron reactions have, and continue to receive attention, functional p-block metal analogues have been far less studied. ${ }^{12}$ Recent work has shown that the chemistry of some heavy main group elements can resemble that of transitionmetal complexes, and main-group metal systems have displayed small-molecule reactivity previously thought to be the exclusive domain of d-block elements. ${ }^{13}$

For the present work, in extending the approach we sought to access a pair of tin(II)/tin(IV) redox couples giving the potential for four-electron transformations within the capsular cryptand environment. We chose to investigate redox reactions involving the group 16 elements, the ensuing finding that clean and informative reactivity was observed for both sulfur and selenium forming the basis of the present work. We note that both the reduction of oxygen to peroxide dianion, and the reduction of sulfur to sulfide ion, are currently targets for the development of new battery chemistries; ${ }^{14}$ fundamental studies such as the present one have the potential to reveal how the reduction processes may become controlled and selective in response to the utilization of a pre-organized architecture.

\section{Results and discussion}

Double insertion of tin(II) or lead(II) into the cryptand proceeds upon treatment of $m \mathrm{BDCA}-5 \mathrm{t}-\mathrm{H}_{6}$ (ref. 15) with $\mathrm{KO}^{t} \mathrm{Bu}$ in the presence of $\mathrm{Sn}\left[\mathrm{N}\left(\mathrm{SiMe}_{3}\right)_{2}\right]_{2}$ or $\mathrm{Pb}\left[\mathrm{N}\left(\mathrm{SiMe}_{3}\right)_{2}\right]_{2}$ (ref. 16) in THF. This procedure affords the $\left[\mathrm{K}_{2}(\mathrm{THF})\right]\left[\mathrm{Sn}_{2}(m \mathrm{BDCA}-5 \mathrm{t})\right]\left(\left[\mathrm{K}_{2}(\mathrm{THF})\right]\right.$ 


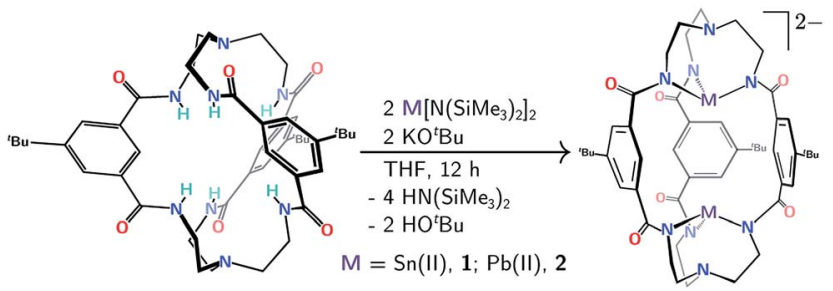

Scheme 1 Protocol for double $\mathrm{Sn}(\Perp)$ or $\mathrm{Pb}(I)$ insertion into the $m \mathrm{BDCA}-5 \mathrm{t}-\mathrm{H}_{6}$ cryptand (together with hexadeprotonation) to generate $\left[\mathrm{Sn}_{2}(m \mathrm{mDCA}-5 \mathrm{t})\right]^{2-}(1)$ and $\left[\mathrm{Pb}_{2}(m \mathrm{mBCA}-5 \mathrm{t})\right]^{2-}(2)$.

[1]) and $\left[\mathrm{K}_{2}(\mathrm{THF})\right]\left[\mathrm{Pb}_{2}(m \mathrm{BDCA}-5 \mathrm{t})\right]\left(\left[\mathrm{K}_{2}(\mathrm{THF})\right][2]\right)$ salt complexes (Scheme 1) as colorless powders in 68 , and $69 \%$ yield, respectively. In their ${ }^{1} \mathrm{H}$ NMR spectra, both 1 (Fig. S1†) and 2 (Fig. S7†) display two resonances corresponding to the aryl protons of the three phenylene spacers, and four resonances are observed for the tren (tren $=$ tris-2-aminoethylamine) methylene residues, suggesting that these bimetallic dianions retain their approximate $C_{3 \mathrm{~h}}$ symmetry in solution at room temperature. Complexes 1 and 2 display single resonances in their ${ }^{119} \mathrm{Sn}\left\{{ }^{1} \mathrm{H}\right\}$ $\operatorname{NMR}\left(I=1 / 2, \delta-381.6 \mathrm{ppm}\right.$, DMSO- $d_{6}$, Fig. $\left.5 \mathrm{c}\right)$, and ${ }^{207} \mathrm{~Pb}$ NMR spectra $\left(I=1 / 2, \delta 2641.4 \mathrm{ppm}\right.$, DMSO- $d_{6}$, Fig. S9†), similarly consistent with the presence of a horizontal mirror plane now relating the tin and lead ions in their $C_{3 \mathrm{~h}}$ geometry. The formulation of both dianions $\mathbf{1}$ and $\mathbf{2}$ has also been confirmed by ESI-MS (-) with $m / z$ values of 541.12 (calc'd, 541.13 , Fig. $S 4 \dagger$ ), and 630.18 (calc'd, 630.21, Fig. S10†), respectively.

Crystals of both 1 and 2 as their [K(Kryptofix 2,2,2)] salts were grown by vapor diffusion of $\mathrm{Et}_{2} \mathrm{O}$ into saturated DMF solutions over the course of $48 \mathrm{~h}$ at $23{ }^{\circ} \mathrm{C}$. Single-crystal X-ray diffraction studies provided the structures of $\mathbf{1}$ and $\mathbf{2}$ shown in Fig. 1 and S51, $\dagger$ respectively. [K(Kryptofix 2,2,2) $]_{2}[\mathbf{1}]$ and $\left[\mathrm{K}(\text { Kryptofix 2,2,2) }]_{2}[2]\right.$ are isostructural, crystallizing in the hexagonal space group $P 6_{3} / m$, with the bimetallic $\mathbf{M} \cdots \mathbf{M}$ cores lying on a crystallographic three-fold axis of rotation. Both anions 1 and $\mathbf{2}$ have effective $C_{3 \mathrm{~h}}$ point group symmetry with the metal centers adopting a trigonal pyramidal coordination

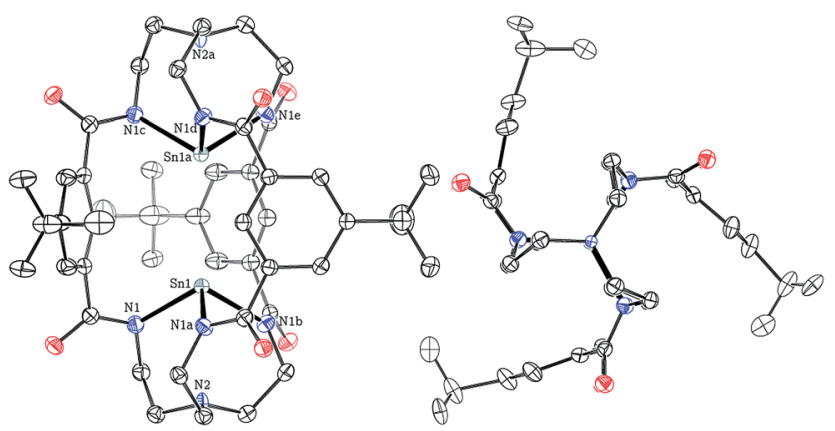

Fig. 1 Solid-state structure of $\left[S n_{2}(m B D C A-5 t)\right]^{2-}(1)$ with thermal ellipsoids (drawn using PLATON ${ }^{17}$ ) shown at the $50 \%$ probability level and with $[K \text { (Kryptofix 2,2,2) }]^{+}$cations, disorder, and hydrogen atoms omitted for clarity. Selected interatomic distances $(\AA)$ and angles $\left(^{\circ}\right)$ : Sn1-N1 3.116(3), Sn1-N2 2.2531(16), Sn1-Sn1a 3.5373(7), N1-Sn1-N1a 100.82(5).

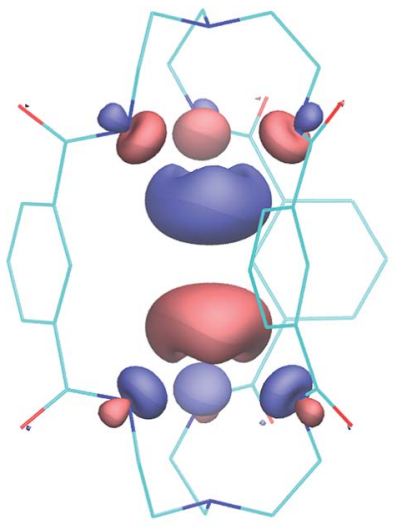

(a) HOMO

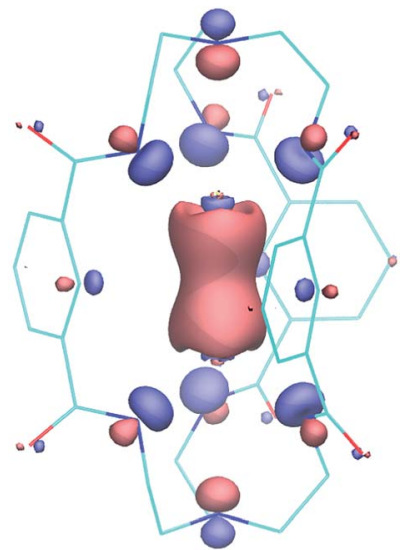

(b) HOMO-1
Fig. $2 \mathrm{HOMO}(\mathrm{a})$ and $\mathrm{HOMO}-1$ (b) of the model dianion [ $\mathrm{Sn}_{2}$ ( $m \mathrm{mBCA}$ $5 \mathrm{H})]^{2-}$ based on the crystallographic coordinates of 1 and computed using $\mathrm{ORCA}^{19}$ at the double-hybrid level of DFT theory ${ }^{20}$ B2PLYP-D3/ def2-TZVPP with corrections for dispersion ${ }^{21}$ and including scalar relativistic effects via the ZORA method. ${ }^{22}$

environment (Fig. 1) as expected for triamidostannate(II) systems. ${ }^{18}$ The solid-state structures of 1 and 2 reveal $\mathrm{Sn} \cdots \mathrm{Sn}$ and $\mathrm{Pb} \cdots \mathrm{Pb}$ intermetal separations of only 3.5373(7), 3.5274(5) $\AA$, respectively, distances which are significantly shorter than the average $\mathrm{M} \cdots \mathrm{M}$ distances that span 6.080 to $6.495 \AA$ for the bimetallic cryptand complexes of metal(II) ions previously reported, where $\mathrm{M}=\mathrm{Mn}, \mathrm{Fe}, \mathrm{Co}, \mathrm{Ni}, \mathrm{Zn}$, and wherein the transition-metal ions adopt the trigonal monopyramidal coordination motif as they sink deeper into the tren-based $\mathrm{N}_{3} \mathrm{~N}$ binding pockets. ${ }^{11}$

Being interested in the potential multi-electron redox reactivity of these p-block metal cryptates, we carried out computations of electronic structure for complex 1 (see Fig. 2 for details); the HOMO consists largely of an out-of-phase combination of the two tin lone pairs, while the HOMO-1 is an inphase combination whose appearance nicely suggests that these metal ions are within bonding distance. The largely metalcentered nature of the HOMO and HOMO-1 electron pairs of $\mathbf{1}$ is fully in line with the expected metal-centered redox activity.

With access to salts of $\mathbf{1}$ and $\mathbf{2}$ on scales approaching $300 \mathrm{mg}$ per synthesis, we were able to initiate exploratory reactivity studies involving the group 16 elements. While the di-lead(II) complex 2 displayed no reaction with chalcogens, the di-tin(II) cryptate 1 was found to react cleanly with both elemental sulfur and selenium. There are hundreds of fully characterized transition-metal cyclic polysulfide and polyselenide complexes known in the literature, ${ }^{23}$ however, significantly fewer examples of polychalcogenide main group metal complexes exist. Polychalcogenide complexes containing group 14 metal ions are especially rare ${ }^{24}$ and there are only two structurally characterized examples we are aware of where a polysulfide or polyselenide ring (with $n>3$ for S, or Se) bridges two group 14 centers. ${ }^{25}$ Even though tin(II) amide compounds are known to react with sulfur and selenium to typically form thermodynamically favored bis- $\mu$-chalcogenide products, ${ }^{26,27}$ we were interested to determine whether the preorganization offered by 


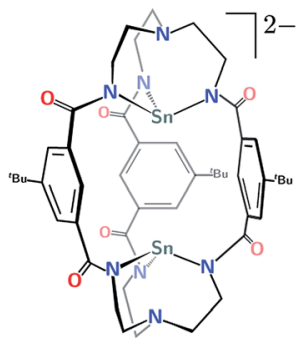

1

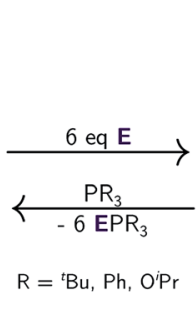

\section{.}

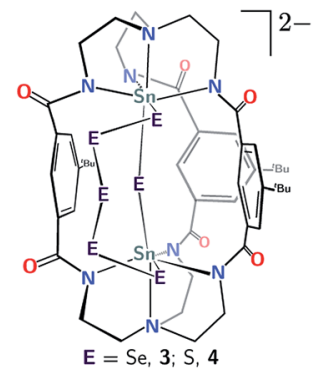

Scheme 2 Reactivity of $\left[S_{2}(m B D C A-5 t)\right]^{2-}(1)$ with elemental selenium and sulfur to generate $\left[\left(\mu-E_{5}\right) S n_{2}(\mu-E)(m B D C A-5 t)\right]^{2-}(E=S e, 3$; $S, 4)$.

the $m \mathrm{BDCA}-5 \mathrm{t}$ cryptand framework would direct the system into new assemblages of atoms otherwise inaccessible in the absence of such a supramolecular construct.

Treatment of 1 with elemental selenium (6 equiv.) in DMF solution was found to elicit a color change from colorless to deep red upon thorough mixing (Scheme 2). After workup, the selectively formed product of this reaction, $\left[\left(\mu-\mathrm{Se}_{5}\right) \mathrm{Sn}_{2}(\mu-\right.$ $\mathrm{Se})(m \mathrm{BDCA}-5 \mathrm{t})]^{2-}(3)$, was isolated in $71 \%$ yield as a brick red solid. The ${ }^{1} \mathrm{H}$ NMR spectrum of 3 (Fig. S12 $\dagger$ ) features three distinct tert-butyl resonances, each with integrations of nine protons, and six aryl resonances with integrations of one and two protons in a $1: 1$ ratio. The ${ }^{119} \mathrm{Sn}$ NMR spectrum of 3 consists of one singlet $\left(\delta-876.5\right.$ ppm, Fig. $5 \mathrm{a},{ }^{1} J_{119_{\mathrm{sn}}-77_{\mathrm{se}}}=3381$ $\mathrm{Hz}$ ), and the ${ }^{77} \mathrm{Se}$ NMR spectrum contains four resonances that are attributed to the four distinct selenium environments of complex 3. The resonances located at $\delta 537.2$, and $884.4 \mathrm{ppm}$ contain well-resolved satellite peaks corresponding to ${ }^{1} J_{119_{\mathrm{Sn}}}-77_{\mathrm{se}}$ coupling of 3371 and $785 \mathrm{~Hz}$, respectively (Fig. 3). ${ }^{28}$ While the ${ }^{1} \mathrm{H}$ NMR spectrum revealed that the three arms of the cryptand are inequivalent, the ${ }^{119} \mathrm{Sn}$ NMR data indicate that 3 contains only one tin environment, indicating that a lowering of symmetry from $C_{3 \mathrm{~h}}$ to $C_{\mathrm{s}}$ has occurred through the reaction of 1 with selenium.

A solid-state structure established the identity of this species as $\left[\mathrm{K}_{2}(\mathrm{DMF})_{3}\right]\left[\left(\mu-\mathrm{Se}_{5}\right) \mathrm{Sn}_{2}(\mu-\mathrm{Se})\left(m \mathrm{BDCA}^{-5 \mathrm{t}}\right)\right](3)$, and Fig. 4 shows a thermal ellipsoid plot of the dianion in this complex salt. X-ray

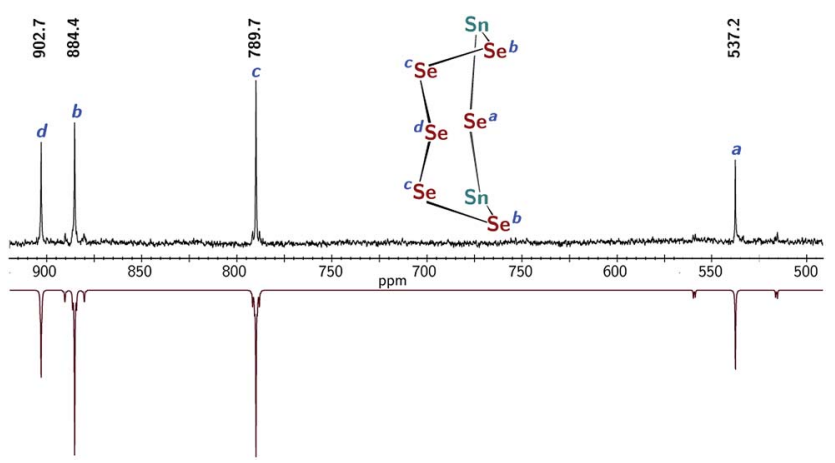

Fig. 3 Experimental ${ }^{77} \mathrm{Se}$ NMR spectrum of 3 (top, DMSO- $d_{6}, 76.3$ $\mathrm{MHz}, 20^{\circ} \mathrm{C}$ ), and simulated spectrum (bottom) showing satellite peaks corresponding to the $J_{119_{\mathrm{Sn}}-77_{\mathrm{se}}}$ coupling.

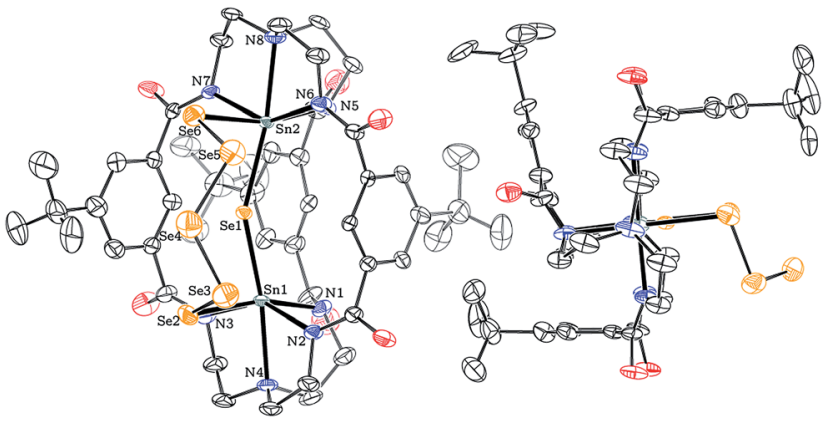

Fig. 4 Solid-state structure of $\left[\left(\mu-\mathrm{Se}_{5}\right) \mathrm{Sn}_{2}(\mu-\mathrm{Se})(m \mathrm{mDCA}-5 \mathrm{t})\right]^{2-}$ (3) with thermal ellipsoids (drawn using PLATON ${ }^{17}$ ) shown at the $50 \%$ probability level. $\mathrm{K}^{+}$cations, DMF solvent molecules, disorder, and $\mathrm{H}$ atoms omitted for clarity. Selected interatomic distances $(\AA)$ and angles $\left({ }^{\circ}\right)$ : Sn1-Sn2 4.932(1), Sn1-Se1 2.578(2), Sn2-Se1 2.605(2), Sn1Se2 2.726(3), Sn2-Se6 2.710(3), Sn1-N2 2.243(16), Sn1-N3 2.235(16), Sn1-N4 2.354(14), Sn2-N5 2.241(18), Sn2-N6 2.251(16), Sn2-N7 2.248(17), Sn2-N8 2.343(14), Sn1-Se1-Sn2 144.20(8), N3-Sn1-N1 86.8(18), N2-Sn1-N1 90.3(17), N3-Sn1-Se2 88.8(15), N2-Sn1-Se2 86.0(15), N5-Sn2-N7 90.1(15), N5-Sn2-N6 95.8(13), N7-Sn2-Se6 87.0(12), N6-Sn2-Se6 80.5(10).

quality dark red crystals of $\left[\mathrm{K}_{2}(\mathrm{DMF})_{3}\right][3]$ were grown by vapor diffusion of diethyl ether into a saturated DMF solution of the salt over the course of $12 \mathrm{~h}$ at $23{ }^{\circ} \mathrm{C}$. The solid-state molecular structure of 3 reveals that the two $\mathrm{Sn}(\mathrm{Iv})$ ions reside in a distorted octahedral environment, each coordinated to the three carboxamide nitrogen atoms from the cryptand as well as one $\mu$ $\mathrm{Se}^{2-}$ ligand and one selenium from the five membered ${ }^{-} \mathrm{Se}(\mathrm{Se})_{3} \mathrm{Se}^{-}$pentaselenide chain that links the two tin(Iv) centers. The observed molecular structure of dianion 3 provides the first glimpse of a conformation in which two cryptand arms are splayed apart in a manner that permits the pentaselenide chain to bridge the tin(Iv) ions in between them, revealing a degree of flexibility we had not previously appreciated for this type of bimetallic hexacarboxamide ligand architecture. The selective formation of this product shows that elemental selenium reacts with complete consumption of all four reducing equivalents stored in the di-tin(II) reservoir of dianion $\mathbf{1}$, while the level of reduction of the elemental selenium, to $\mathrm{Se}^{2-}$ and $\mathrm{Se}_{5}{ }^{2-}$, is such that only one-third of the complete oxidizing power of $6 \mathrm{Se}^{0}$ is quenched and four reducible Se-Se bonds remain.

The UV-Vis spectrum of 3 in DMF solution shows two major absorptions located at $\lambda_{\max }=452\left(\varepsilon=4207 \mathrm{M}^{-1} \mathrm{~cm}^{-1}\right)$, and 585 $\left(\varepsilon=842 \mathrm{M}^{-1} \mathrm{~cm}^{-1}\right) \mathrm{nm}(0.26 \mathrm{mM}$, Fig. S16 $\dagger)$. Both observed bands are in good agreement with the literature reported absorption values for $\mathrm{Se}_{6}{ }^{2-}$ of $\lambda_{\max }=440$ and $598 \mathrm{~nm}$ in DMA solution. $^{29}$

Similarly, the reactivity of $\mathbf{1}$ with elemental sulfur was investigated. Treatment of 1 with $3 / 4$ eq. $S_{8}$ in DMF solution elicits a rapid color change from colorless to blue green. Addition of $\mathrm{Et}_{2} \mathrm{O}$ to the crude reaction mixture results in the precipitation of the $\left[\mathrm{K}_{2}(\mathrm{DMF})_{3}\right]\left[\left(\mu-\mathrm{S}_{5}\right) \mathrm{Sn}_{2}(\mu-\mathrm{S})(m \mathrm{BDCA}-5 \mathrm{t})\right]$ complex (4, Scheme 2) as a bright yellow solid in $63 \%$ yield. Although suitable crystals were not obtained for an X-ray diffraction study, the structure of the sulfur-containing product 
can be deduced from its NMR spectra. The NMR properties of 4 are similar to those of 3 , with three distinct tert-butyl resonances and six aryl resonances in its ${ }^{1} \mathrm{H}$ NMR spectrum (Fig. S18 $\dagger$ ), and one resonance in its ${ }^{119} \mathrm{Sn}$ NMR spectrum $(\delta=$ -559.7 ppm, Fig. 5b), consistent with $\mu-S_{5}$ and $\mu-S$ ligands bridging two tin centers. The data again indicate that reaction of 1 with elemental sulfur results in oxidation of both $\mathrm{Sn}$ (II) centers to $\mathrm{Sn}$ (Iv) with concomitant partial reduction of sulfur by a total of four electrons.

Reactions of tin(II) amide compounds with oxygen, sulfur, or selenium typically result in complexes containing terminal $\mathrm{Sn}=\mathrm{E}$ bonds $^{30}$ or thermodynamically favored bis- $\mu$-chalcogenide products, ${ }^{27}$ with complete reduction to the oxide, sulfide, or selenide ion, $\mathrm{E}^{2-}(\mathrm{E}=\mathrm{O}, \mathrm{S}, \mathrm{Se})$. In our system, however, the preorganization of the cryptand architecture has offered kinetic control of the products obtained such that the chalcogen reduction is incomplete and we have stopped at the level of two electrons for every three sulfur/selenium atoms. Such partial chalcogen reduction calls to mind results from Richeson et al. who reported the reaction of a mononuclear tin(II) amide with elemental sulfur to provide a bidentate chelating $\mathrm{S}_{4}{ }^{2-}$ ligand. ${ }^{31}$

We note that treatment of 1 with sulfur-atom-transfer (SAT) reagents such as propylene sulfide and $\mathrm{Ph}_{3} \mathrm{SbS}^{32}$ led to no observable reaction. The five-membered chalcogen rings of 3 and $\mathbf{4}$ are favored over any other ring size, as treatment of 1 with $>6$ equiv. Se or $S$ results in exclusive formation of 3 and 4 , and reaction of 1 with $<6$ equiv. Se or $S$ results in incomplete conversion of 1 to 3 or $\mathbf{4}$, respectively. The exclusive isolation of the $\left[\left(\mu-\mathrm{E}_{5}\right) \mathrm{Sn}_{2}(\mu-\mathrm{E})(m \mathrm{BDCA}-5 \mathrm{t})\right]^{2-}(\mathrm{E}=\mathrm{Se}, \mathrm{S})$ polychalcogenide complexes is likely due to the favorable geometry as a result of the formation of the five membered chalcogenide ring, as the solid-state structure of 3 shows the $\mathrm{Se}_{5}$ ring is similar in size to one of the aromatic spacer arms of the cryptand. A similar phenomenon has been observed for polychalcogenide tin $\mathrm{Tb}$ complexes ( $\mathrm{Tb}=2,4,6$-tris[bis(trimethylsilyl)methyl $]$ phenyl) reported by Okazaki. ${ }^{33}$

Complex $\mathbf{4}$ is cleanly isolated as a yellow solid; however, when the yellow solid is dissolved in DMF or DMSO, the color of the resulting solution is dark blue-green. In order to investigate the cause of this color change, both solution and solid-state UV-

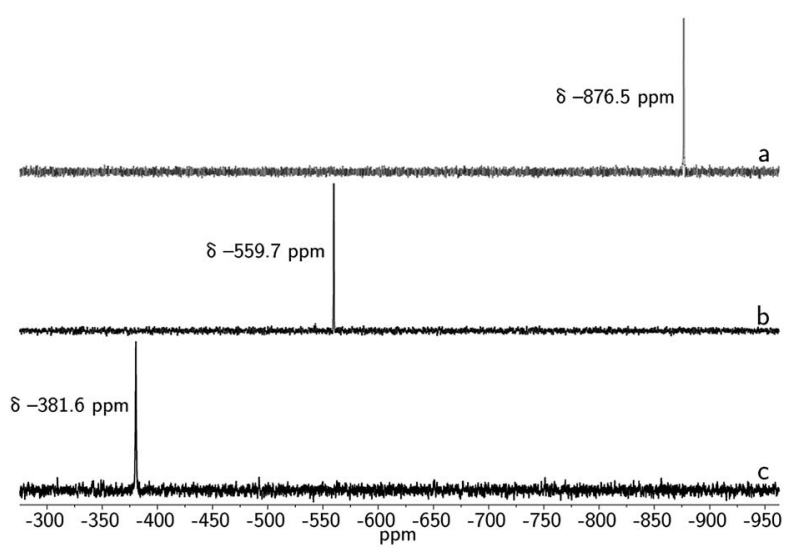

Fig. $5{ }^{119} \mathrm{Sn}\left\{{ }^{1} \mathrm{H}\right\}$ NMR spectra of $3(\mathrm{a}), 4$ (b), and 1 (c) taken in DMSO- $d_{6}$ at $20^{\circ} \mathrm{C}(149 \mathrm{MHz})$.

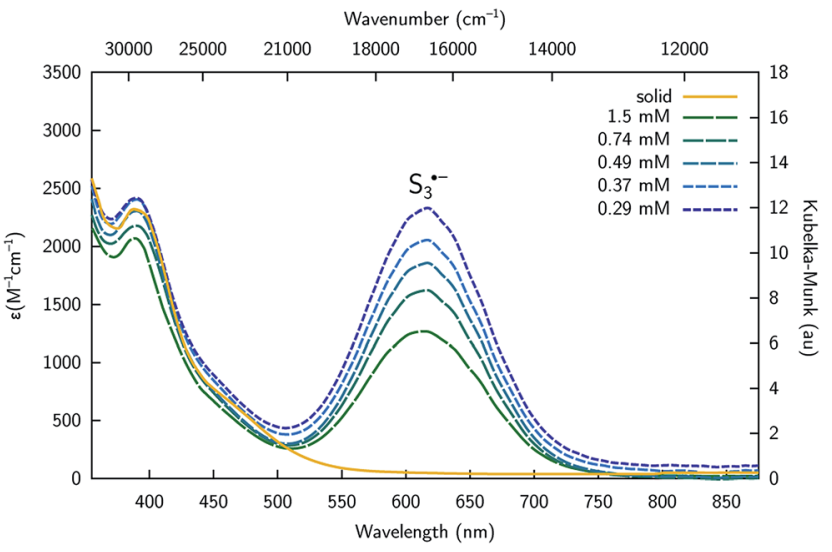

Fig. 6 UV-Vis spectra of $\left[\mathrm{K}_{2}(\mathrm{DMF})_{3}\right][4]$ in the solid state (yellow), and in DMF at $20^{\circ} \mathrm{C}$ collected at varying concentration showing the presence of $S_{3}^{\cdot-}\left(\lambda_{\max }=617 \mathrm{~nm}\right)$ in solution.

Vis spectra of 4 were obtained. The solution UV-Vis spectrum of 4 in DMF shows two major absorptions at $\lambda_{\max }=392$ and 617 $\mathrm{nm}$, while the diffuse reflectance UV-Vis spectrum shows only one major absorption at $\lambda_{\max }=392 \mathrm{~nm}$ (Fig. 6). The absorption at $\lambda_{\max }=617 \mathrm{~nm}$ that is only present in the solution spectrum is consistent with the literature reported absorption band of trisulfur radical anion $\left(\mathrm{S}_{3}{ }^{-}\right) \cdot{ }^{34}$ These data suggest that $\mathrm{S}_{3}{ }^{-}$ dissociates from the complex in solution possibly as indicated by eqn (1), and is therefore responsible for the marked difference in color between solution and the solid state for this system. The trisulfur radical anion has been extensively studied and is known as the blue color center in ultramarine pigments in which this highly reactive species is trapped within a zeolite framework; $\mathrm{S}_{3}{ }^{-}$is also responsible for the blue color in the naturally occurring mineral, lapis lazuli. ${ }^{35}$

$$
\left[\left(\mu-\mathrm{S}_{5}\right) \mathrm{Sn}_{2}(\mu-\mathrm{S}) \underset{\mathbf{4}}{(m \mathrm{BDCA}-5 \mathrm{t})]^{2-}} \stackrel{\rightarrow}{\longleftarrow}\left[\mathrm{Sn}_{2}(m \mathrm{BDCA}-5 \mathrm{t})\right]+2 \mathrm{~S}_{3} \cdot-\right.
$$

It is known that $\mathrm{S}_{3}{ }^{\cdot-}$ is readily formed from its $\mathrm{S}_{6}{ }^{2-}$ dimer via dissociation in an entropy-driven process that is favored by high temperatures and in dilute solutions in highly polar solvents such as DMF, HMPA, and DMSO. ${ }^{36}$ These properties are consistent with observations made using the present system, as variable temperature UV-Vis spectra of complex 4 display a significant increase in the amount of $\mathrm{S}_{3}{ }^{-}$as the temperature of the solution increases from 15 to $85^{\circ} \mathrm{C}$ (Fig. S24†). Similarly, UV-Vis studies of complex 4 indicate that the amount of $\mathrm{S}_{3}{ }^{\cdot-}$ in solution increases as the concentration of $\mathbf{4}$ decreases as indicated by its molar extinction value that maximizes at $\varepsilon=2330$ $\mathrm{M}^{-1} \mathrm{~cm}^{-1}$ (0.29 mM, Fig. 6). The equilibrium constant ( $\left.K_{\mathrm{eq}}\right)$ for $\mathrm{S}_{3}{ }^{\cdot-}$ dissociation from complex 1 based upon eqn (1) was calculated to be $0.012 \pm 0.002$ in DMF solution at $20^{\circ} \mathrm{C}$, indicating the equilibrium lies heavily to the left. The presence of $\mathrm{S}_{3}{ }^{-}$- was also confirmed by electron paramagnetic resonance (EPR) spectroscopy, where a broad signal centred at $g=2.0290$ was observed in DMF solution at $20^{\circ} \mathrm{C}$ (Fig. S25 $\dagger$ ). This signal is 
in agreement with the literature reported EPR signal of $\mathrm{S}_{3}{ }^{\cdot-} \cdot{ }^{37}$ Therefore, the observed data suggest that in solution, the sulfur atoms of complex 4 undergo dissociation from the di-tin cryptand to release $\mathrm{S}_{3} \cdot{ }^{\cdot-}$.

The presence of $\mathrm{S}_{3}{ }^{\cdot-}$ upon dissolution of 4 may be a result of initial release of $\mathrm{S}_{6}{ }^{2-}$ followed by dissociation into two equivalents of $\mathrm{S}_{3}{ }^{-}-$. According to this overall stoichiometry, dissociation of two equivalents of $\mathrm{S}_{3}{ }^{-}$- from the dianionic complex 4 would require the concomitant formation of a neutral $\left[\mathrm{Sn}_{2}-\right.$ (mBDCA-5t)] species. Although this is perhaps the most straightforward explanation, we cannot definitively rule out $\mathrm{S}_{5}{ }^{2-}$ or $\mathrm{S}_{4}{ }^{2-}$ as the source of $\mathrm{S}_{3}{ }^{--}$. While more work is required to substantiate this proposal, such a postulated neutral $\left[\mathrm{Sn}_{2}-\right.$ $(m$ BDCA-5t $)]$ species may exist as a $\mathrm{Sn}-\mathrm{Sn}$ bonded hexaaminodistannane analogous to one which Gade et al. obtained upon oxidative coupling of a tin(II) triamidostannate and for which the $\mathrm{Sn}-\mathrm{Sn}$ interatomic distance was reported to be 2.8204(4) $\AA^{38}$ The metal-metal single bond in such a species corresponds to the HOMO-1 of complex 1 (Fig. 2b).

In an effort to drive to full completion the level of sulfur/ selenium reduction in this system, we probed the reaction of 3 and 4 with $\mathrm{PR}_{3}$ reductants $\left(\mathrm{R}={ }^{t} \mathrm{Bu}, \mathrm{Ph}, \mathrm{O}^{\mathrm{i}} \mathrm{Pr}\right.$, Scheme 2). Proceeding accordingly, we found that treatment of either complex with $\mathrm{PR}_{3}$ (6 equiv.) resulted in abstraction of all six chalcogen atoms and quantitative regeneration of di-tin(II) complex 1! Incomplete conversion of $\mathbf{3}$ and $\mathbf{4}$ to $\mathbf{1}$ was the result when using $<6$ equiv. $\mathrm{PR}_{3}$, with no other species observed by ${ }^{1} \mathrm{H}$ or ${ }^{119} \mathrm{Sn}$ NMR spectroscopy. Treatment of either 3 or 4 with $\mathrm{PMes}_{3}$ (excess), however, led to no observed reaction, this being explicable in terms of steric effects. Dechalcogenation of transition $^{39}$ and group 14 (ref. 31 and 40) metal cyclic polychalcogenide complexes is commonly accomplished using tertiary phosphines or electron deficient alkenes and alkynes. These reactions, however, typically result in only partial reduction in the size of the chalcogen ring or conversion to the typical bis- $\mu$-chalcogen thermodynamic product instead of complete dechalcogenation. The present polychalcogen/di-tin cryptand complexes are very unusual inasmuch as $\mathrm{PR}_{3}$ compounds are capable of complete de-chalcogenation and reduction of tin back to the +2 oxidation state, suggesting in turn that the macrobicyclic nature of bimetallic complex 1 imbues the tin(II) oxidation state with comparatively greater stability than is typical sans such structural constraints.

\section{Acknowledgements}

This work was supported by NSF under the NSF Center CHE1305124. This work also used the shared facilities in the Center for Materials Science and Engineering (CMSE) at MIT. Amanda Stubbs is thanked for assistance collecting diffuse reflectance UV-Vis spectra.

\section{References}

1 (a) G. T. Babcock and M. Wikstrom, Nature, 1992, 356, 301309; (b) R. J. Debus, Biochim. Biophys. Acta, 1992, 1102, 269-
352; (c) B. K. Burgess, Chem. Rev., 1990, 90, 1377-1406; (d) M. W. Adams, Biochim. Biophys. Acta, 1990, 1020, 115-145.

2 (a) C. Gueutin, D. Lexa, J.-M. Savéant and M. Momenteau, J. Electroanal. Chem. Interfacial Electrochem., 1988, 256, 219222; (b) K. M. Kadish, L. Frémond, Z. Ou, J. Shao, C. Shi, F. C. Anson, F. Burdet, C. P. Gros, J.-M. Barbe and R. Guilard, J. Am. Chem. Soc., 2005, 127, 5625-5631.

3 (a) G. Proni, G. Pescitelli, X. Huang, N. Q. Quraishi, K. Nakanishi and N. Berova, Chem. Commun., 2002, 15901591; (b) V. V. Borovkov, J. M. Lintuluoto and Y. Inoue, Org. Lett., 2002, 4, 169-171.

4 (a) Y. Shimazaki, T. Nagano, H. Takesue, B.-H. Ye, F. Tani and Y. Naruta, Angew. Chem., Int. Ed., 2004, 43, 98-100; (b) R. Konduri, N. R. de Tacconi, K. Rajeshwar and F. M. MacDonnell, J. Am. Chem. Soc., 2004, 126, 1162111629; (c) A. F. Heyduk and D. G. Nocera, Science, 2001, 293, 1639-1641; (d) D. S. Laitar, P. Müller and J. P. Sadighi, J. Am. Chem. Soc., 2005, 127, 17196-17197; (e) J. A. Gilbert, D. S. Eggleston, W. R. Murphy, D. A. Geselowitz, S. W. Gersten, D. J. Hodgson and T. J. Meyer, J. Am. Chem. Soc., 1985, 107, 3855-3864; (f) J. W. Jurss, R. S. Khnayzer, J. A. Panetier, K. A. El Roz, E. M. Nichols, M. Head-Gordon, J. R. Long, F. N. Castellano and C. J. Chang, Chem. Sci., 2015, 6, 4954-4972.

5 (a) F. Liu, T. Cardolaccia, B. J. Hornstein, J. R. Schoonover and T. J. Meyer, J. Am. Chem. Soc., 2007, 129, 2446-2447; (b) J. M. Basset and R. Ugo, in On the Origins and Development of "Surface Organometallic Chemistry", WileyVCH Verlag GmbH \& Co. KGaA, 2009, pp. 1-21.

6 (a) J. P. Collman, P. S. Wagenknecht and J. E. Hutchison, Angew. Chem., Int. Ed. Engl., 1994, 33, 1537-1554; (b) Y. Deng, C. J. Chang and D. G. Nocera, J. Am. Chem. Soc., 2000, 122, 410-411.

7 (a) C. K. Chang, H. Y. Liu and I. Abdalmuhdi, J. Am. Chem. Soc., 1984, 106, 2725-2726; (b) J. P. Collman and K. Kim, J. Am. Chem. Soc., 1986, 108, 7847-7849; (c) S. Fukuzumi, K. Okamoto, Y. Tokuda, C. P. Gros and R. Guilard, J. Am. Chem. Soc., 2004, 126, 17059-17066; (d) J. Rosenthal and D. G. Nocera, Acc. Chem. Res., 2007, 40, 543-553.

8 J. P. Collman, J. E. Hutchison, M. A. Lopez, R. Guilard and R. A. Reed, J. Am. Chem. Soc., 1991, 113, 2794-2796.

9 Y. Naruta and K. Maruyama, J. Am. Chem. Soc., 1991, 113, 3595-3596.

10 G. E. Alliger, P. Mueller, C. C. Cummins and D. G. Nocera, Inorg. Chem., 2010, 49, 3697-3699.

11 G. E. Alliger, P. Mueller, L. H. Do, C. C. Cummins and D. G. Nocera, Inorg. Chem., 2011, 50, 4107-4115.

12 (a) G. H. Spikes, J. C. Fettinger and P. P. Power, J. Am. Chem. Soc., 2005, 127, 12232-12233; (b) Y. Peng, B. D. Ellis, X. Wang, J. C. Fettinger and P. P. Power, Science, 2009, 325, 1668-1670.

13 (a) P. P. Power, Nature, 2010, 463, 171-177; (b) A. V. Protchenko, J. I. Bates, L. M. A. Saleh, M. P. Blake, A. D. Schwarz, E. L. Kolychev, A. L. Thompson, C. Jones, P. Mountford and S. Aldridge, J. Am. Chem. Soc., 2016, 138, 4555-4564. 
14 P. G. Bruce, S. A. Freunberger, L. J. Hardwick and J.-M. Tarascon, Nat. Mater., 2011, 11, 19-29.

15 Explanation of $m$ BDCA-5 $-\mathrm{H}_{6}$ shorthand: $m$ BDCA denotes a meta-substituted derivative of benzene dicarboxylic acid for the three spacers joining two tren, tris-2aminoethylamine, end caps. $5 t$ refers to a tert-butyl group at the 5-position of each substituted benzene spacer, and $\mathrm{H}_{n}$ is the state of protonation of the six carboxamide groups $(n=0-6)$.

16 M. J. S. Gynane, D. H. Harris, M. F. Lappert, P. P. Power, P. Riviere and M. Riviere-Baudet, J. Chem. Soc., Dalton Trans., 1977, 2004-2009.

17 A. L. Spek, Acta Crystallogr., Sect. D: Biol. Crystallogr., 2009, 65, 148-155.

18 (a) L. Gade, Eur. J. Inorg. Chem., 2002, 2002, 1257-1268; (b) A. K. Singh and B. Sonali, Main Group Metal Chemistry, 2011, vol. 26, pp. 155-211.

19 F. Neese, Wiley Interdiscip. Rev.: Comput. Mol. Sci., 2012, 2, 73-78.

20 (a) S. Grimme, J. Chem. Phys., 2006, 124, 034108; (b) L. Goerigk and S. Grimme, Phys. Chem. Chem. Phys., 2011, 13, 6670 .

21 (a) S. Grimme, S. Ehrlich and L. Goerigk, J. Comput. Chem., 2011, 32, 1456-1465; (b) S. Grimme, J. Antony, S. Ehrlich and H. Krieg, J. Chem. Phys., 2010, 132, 154104.

22 (a) E. van Lenthe, A. Ehlers and E.-J. Baerends, J. Chem. Phys., 1999, 110, 8943-8953; (b) D. A. Pantazis, X.-Y. Chen, C. R. Landis and F. Neese, J. Chem. Theory Comput., 2008, 4, 908-919.

23 (a) M.-L. Tsai, C.-C. Chen, I.-J. Hsu, S.-C. Ke, C.-H. Hsieh, K.-A. Chiang, G.-H. Lee, Y. Wang, J.-M. Chen, J.-F. Lee and W.-F. Liaw, Inorg. Chem., 2004, 43, 5159-5167; (b) S.-B. Yu and R. Holm, Polyhedron, 1993, 12, 263-266; (c) P. Cartwright, R. Gillard, E. Sillanpaa and J. Valkonen, Polyhedron, 1991, 10, 2501-2509; (d) E. Muller, J. L. Petersen and L. F. Dahl, J. Organomet. Chem., 1976, 111, 91-112; (e) Y. Wakatsuki, H. Yamazaki and C. Cheng, J. Organomet. Chem., 1989, 372, 437-445; (f) G.-N. Liu, W.-J. Zhu, M.-J. Zhang, B. Xu, Q.-S. Liu, Z.-W. Zhang and C. Li, J. Solid State Chem., 2014, 218, 109-115; $(g)$ T.-N. Chen, F.-C. Lo, M.-L. Tsai, K.-N. Shih, M.-H. Chiang, G.-H. Lee and W.-F. Liaw, Inorg. Chim. Acta, 2006, 359, 2525-2533; (h) A. P. Ginsberg, J. H. Osborne and C. R. Sprinkle, Inorg. Chem., 1983, 22, 1781-1790; (i) N. Albrecht and E. Weiss, J. Organomet. Chem., 1988, 355, 89-98.
24 (a) N. Tokitoh, T. Matsumoto and R. Okazaki, Tetrahedron Lett., 1991, 32, 6143-6146; (b) N. Tokitoh, H. Suzuki, T. Matsumoto, Y. Matsuhashi, R. Okazaki and M. Goto, J. Am. Chem. Soc., 1991, 113, 7047-7049; (c) Y. Matsuhashi, N. Tokitoh and R. Okazaki, Organometallics, 1994, 13, 4387-4397.

25 (a) T. Matsumoto, Y. Matsui, M. Ito and K. Tatsumi, Chem.Asian J., 2008, 3, 607-613; (b) M. Bouska, L. Dostal, A. Ruzicka, L. Benes and R. Jambor, Chem.-Eur. J., 2011, 17, 450-454.

26 Y. Zhou and D. S. Richeson, J. Am. Chem. Soc., 1996, 118, 10850-10852.

27 I. Schranz, L. Grocholl, C. J. Carrow, L. Stahl and R. J. Staples, J. Organomet. Chem., 2008, 693, 1081-1095.

28 D. J. Eisler and T. Chivers, Chem.-Eur. J., 2006, 12, 233-243. 29 (a) A. Ahrika, J. Robert, M. Anouti and J. Paris, New J. Chem., 2001, 25, 741-746; (b) A. Ahrika and J. Paris, New J. Chem., 1999, 23, 1177-1180.

30 T. Chivers and D. J. Eisler, Angew. Chem., Int. Ed., 2004, 43, 6686-6689.

31 S. R. Foley, G. P. A. Yap and D. S. Richeson, Organometallics, 1999, 18, 4700-4705.

32 J. P. Donahue, Chem. Rev., 2006, 106, 4747-4783.

33 Y. Matsuhashi, N. Tokitoh, R. Okazaki, M. Goto and S. Nagase, Organometallics, 1993, 12, 1351-1358.

34 T. Chivers and I. Drummond, Inorg. Chem., 1972, 11, 25252527.

35 R. J. H. Clark and D. G. Cobbold, Inorg. Chem., 1978, 17, 3169-3174.

36 (a) T. Chivers, Nature, 1974, 252, 32-33; (b) T. Chivers and P. J. W. Elder, Chem. Soc. Rev., 2013, 42, 5996-6005.

37 (a) V. Pinon, E. Levillain and J. P. Lelieur, J. Phys. Chem., 1991, 95, 6462-6465; (b) G. Zhang, H. Yi, H. Chen, C. Bian, C. Liu and A. Lei, Org. Lett., 2014, 16, 6156-6159.

38 M. Lutz, M. Haukka, T. A. Pakkanen and L. H. Gade, Z. Anorg. Allg. Chem., 2003, 629, 182-184.

39 (a) C. M. Bolinger, T. B. Rauchfuss and S. R. Wilson, J. Am. Chem. Soc., 1981, 103, 5620-5621; (b) M. Draganjac and T. B. Rauchfuss, Angew. Chem., Int. Ed., 1985, 24, 742-757; (c) D. M. Giolando, M. Papavassiliou, J. Pickardt, T. B. Rauchfuss and R. Steudel, Inorg. Chem., 1988, 27, 2596-2600; (d) T. B. Rauchfuss, Inorg. Chem., 2004, 43, 1426.

40 (a) M. Saito, N. Tokitoh and R. Okazaki, J. Am. Chem. Soc., 1997, 119, 11124-11125; (b) N. Tokitoh, T. Matsumoto and R. Okazaki, Tetrahedron Lett., 1992, 33, 2531-2534. 